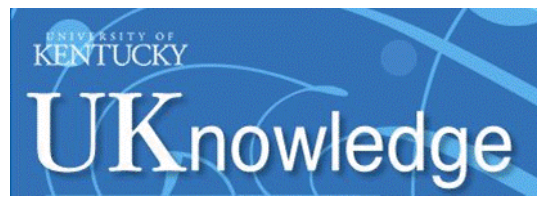

University of Kentucky

UKnowledge

Power and Energy Institute of Kentucky Faculty Publications

6-2019

\title{
WAVED: A Coreless Axial Flux PM Motor for Drive Systems with Constant Power Operation
}

\author{
Narges Taran \\ University of Kentucky, narges.taran@uky.edu \\ Vandana Rallabandi \\ University of Kentucky, vandana.rallabandi@uky.edu \\ Dan M. Ionel \\ University of Kentucky, dan.ionel@uky.edu
}

Follow this and additional works at: https://uknowledge.uky.edu/peik_facpub

Part of the Power and Energy Commons

Right click to open a feedback form in a new tab to let us know how this document benefits you.

\section{Repository Citation}

Taran, Narges; Rallabandi, Vandana; and Ionel, Dan M., "WAVED: A Coreless Axial Flux PM Motor for Drive Systems with Constant Power Operation" (2019). Power and Energy Institute of Kentucky Faculty Publications. 20.

https://uknowledge.uky.edu/peik_facpub/20

This Conference Proceeding is brought to you for free and open access by the Power and Energy Institute of Kentucky at UKnowledge. It has been accepted for inclusion in Power and Energy Institute of Kentucky Faculty Publications by an authorized administrator of UKnowledge. For more information, please contact UKnowledge@lsv.uky.edu. 


\title{
WAVED: A Coreless Axial Flux PM Motor for Drive Systems with Constant Power Operation
}

\author{
Digital Object Identifier (DOI) \\ https://doi.org/10.1109/ITEC.2019.8790489
}

\section{Notes/Citation Information}

Published in 2019 IEEE Transportation Electrification Conference and Expo (ITEC).

(C) 2019 IEEE Copyright Notice. "Personal use of this material is permitted. Permission from IEEE must be obtained for all other uses, in any current or future media, including reprinting/republishing this material for advertising or promotional purposes, creating new collective works, for resale or redistribution to servers or lists, or reuse of any copyrighted component of this work in other works.

The document available for download is the authors' manuscript version that is accepted for publication. The final published version is copyrighted by IEEE and will be available as: N. Taran, V. Rallabandi, and D. M. Ionel, "WAVED: ACoreless Axial Flux PM Motor for Drive Systems with Constant Power Operation," 2019 IEEE Transportation Electrification Conference and Expo (ITEC), Novi, MI, 2019, pp.1-6. 


\title{
WAVED: A Coreless Axial Flux PM Motor for Drive Systems with Constant Power Operation
}

\author{
Narges Taran, Vandana Rallabandi*, Dan M. Ionel \\ SPARK Lab, ECE Department, University of Kentucky, Lexington, KY, USA \\ narges.taran@uky.edu,vandana.rallabandi@ieee.org,dan.ionel@ieee.org
}

\begin{abstract}
In this paper, a two-phase coreless AFPM machine with wave winding, 2-stators, and 3-rotors for traction applications is studied. A highly general optimization method, employing 3D FEA as the computational engine is employed. Number of poles in addition to other geometrical variables are included as independent optimization variables. A method for extending the speed range by rotating one of the stator discs with respect to the other at constant power operation is proposed. An inverter configuration including $\mathrm{Si}$ and wide band gap devices is proposed to be employed in conjunction with the machine under study. The study includes a comparison of the optimally designed coreless machine with a commercial yokeless and segmented armature electric motor.
\end{abstract}

Index Terms-Coreless, two-phase, wave winding, axial flux PM machine, traction, optimization, number of poles, characteristic current, flux weakening, constant power speed range.

\section{INTRODUCTION}

Electric vehicles (EV) are increasingly gaining popularity due to various reasons including environmental concerns. The electric machine employed in propulsion systems plays a crucial role in its performance. Desired characteristics of the traction motor include a high power density, high torque (for starting), high power (for cruising), low cost and mass, wide speed range, high efficiency, overload capability, high reliability, fault tolerance, low noise, and low torque ripple. Many machine topologies have been proposed and studied for traction applications including variants of PM synchronous machines, induction machines, and switched reluctance machines [1], [2]. Each machine configuration best satisfies some of the requirements and fails to fulfill the others. For instance, induction machines are robust and economical but their efficiency may be lower. Synchronous reluctance machines may have a wider speed range, however, their acoustic noise and low power factor are problematic. Permanent magnet machines may have possible demagnetization issues while their major advantage is higher efficiency and power density.

The topology considered in this study is a two-phase coreless (air-cored) axial flux permanent magnet (AFPM) machine with wave windings considered for drive systems. Henceforth, this motor topology will be referred to as WAVED.

Coreless machines may satisfy the requirements of high efficiency, torque density, overload capability and low mass

* Dr. Vandana Rallabandi was with the SPARK Laboratory, ECE Department, University of Kentucky, Lexington, KY and is now with General Electric, Global Research, Niskayuna, NY.
[3]. These machines feature insignificant core losses in the rotor back iron such that the copper loss comes out to be by far the dominant loss component. The employment of the Litz wire for mitigating additional conductor eddy current losses due to the exposure of the conductors to the air-gap flux in coreless structures is necessary.

This paper discusses the optimal design of such machines using 3D finite element analysis (FEA) as the computational engine. The design variables considered include geometric variables, as well as the number of poles. The objectives are to minimize the mass and the loss. The optimization is performed for the rated torque at the rated speed, as the absence of core loss simplifies the efficiency variation over a driving cycle.

The large electromagnetic air-gap of the coreless configuration reduces characteristic current, and hence limits the speed range. Constant power operation at higher speeds for AFPM machine may be achieved through mechanical adjustment of the airgap by pulling the stator and rotor discs apart [4]. Another approach is employing multiple stator stacks per phase and rotating them relative to each other.

In this paper, constant power is obtained at speeds higher than rated value, by reducing flux linkage through the rotation of the the stators with respect to each other. Two H-bridges are proposed for driving the motor. Asymmetric PWM is used such that two of the switches operate at fundamental frequency, and the other two at switching frequency. In order to maximize the efficiency, the devices switching at fundamental frequency will be Si based, while the switches operating at high frequency can be configured with wide band gap devices.

\section{Two-Phase WAVED Machine TOPOLOGY}

Coreless machines have recently received a lot of attention due to having the potential for the highest efficiency in high speed applications, thanks to elimination of the stator core losses. This is particularly important considering that the target maximum speed for the traction motor is increasing such that it is set to reach at least $20,000 \mathrm{rpm}$ by the year 2020 [5], [6]. High speed motors tend to be lighter due to lower torque requirement [7]. Coreless machines enjoy the additional weight reduction due to the elimination of the stator core. Therefore, considering a coreless topology may be beneficial. Coreless machines have been previously considered for traction applications, for example in solar cars and small aircrafts [8]-[10]. Further improvement in the performance

Authors' manuscript accepted for publication. The final published version is copyrighted by IEEE and will be available as: N. Taran, V. Rallabandi, and D. M. Ionel, "WAVED: A Coreless Axial Flux PM Motor for Drive Systems with Constant Power Operation," 2019 IEEE Transportation Electrification Conference and Expo (ITEC), Novi, MI, 2019, pp. 1-6. (O2019 IEEE Copyright Notice. "Personal use of this material is permitted. Permission from IEEE must be obtained for all other uses, in any current or future media, including reprinting/republishing this material for advertising or promotional purposes, creating new collective works, for resale or redistribution to servers or lists, or reuse of any copyrighted component of this work in other works." 


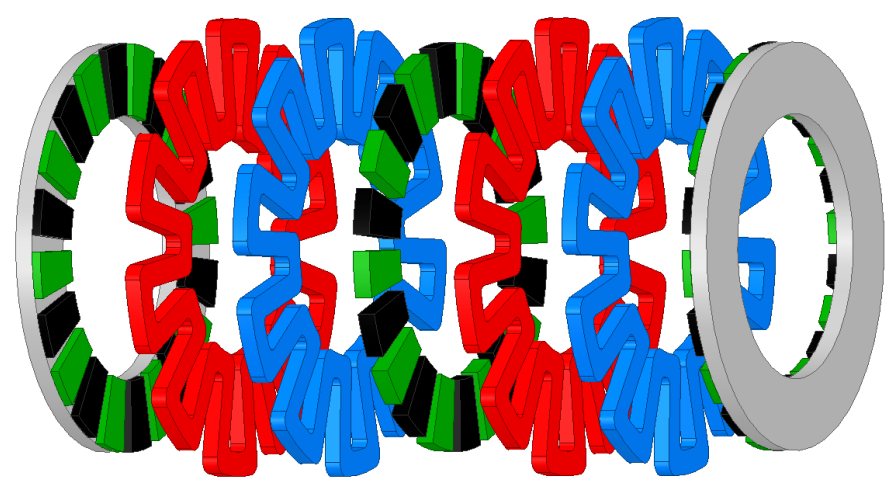

Figure 1. The exploded view of 3D FEA model for a two-phase AFPM motor with wave windings. Each of the two stators has a two-phase winding.

Table I

THE SPECIFICATIONS OF THE TWO-PHASE CORELESS AFPM MACHINE WITH WAVE WINDINGS.

\begin{tabular}{lr}
\hline Max torque & $60 \mathrm{Nm}$ \\
Rated speed & $10,000 \mathrm{rpm}$ \\
Total outer diameter & $265 \mathrm{~mm}$ \\
Axial stack length & $100 \mathrm{~mm}$ \\
\hline
\end{tabular}

and reduction in dimensions and mass can be achieved by employing printed circuit board stator structure as shown for example in [11], [12].

Some advantages of the two-phase coreless WAVED motor include: the coreless machine has virtually zero cogging torque; the armature reaction is negligible; the torque-current characteristics is linear as there is no saturation; the twophase topology can improve fault-tolerance as the coupling between phases is inherently negligible; and the PM excited rotor improves efficiency and torque density. A disadvantage of this machine is high ac copper loss due to eddy currents that can be mitigated by using Litz wire and a careful winding design. Another issue is its low inductance which limits the constant power speed range (CPSR) [13]. This is discussed in detail in a following section.

The exploded view of the machine under study is presented in Fig. 1. For each pole pair there are two coil sides per phase. This symmetrical configuration enables analyzing of only one pole pair, which expedites the 3D FEA design evaluation and makes it feasible to include the number of poles as an optimization variable. The specifications are provided in Table I. The rated torque is selected based on acceleration requirements. The wave winding can also be implemented using printed circuit board technology [12].

The implementation of the two phase topology improves fault tolerance as the mutual coupling between the two phases is very small. This is shown with numerical analysis of the optimally designed two-phase WAVED machine in Fig. 2. It is observed that in the case of the faulty phase short circuit phase operation, the other phase is not considerably affected.
Table II

THE INDEPENDENT VARIABLES FOR OPTIMIZATION.

\begin{tabular}{lrr}
\hline Variable & Minimum & Maximum \\
\hline Pole count & 16 & 38 \\
Split ratio & 0.45 & 0.80 \\
Pole arc / pitch ratio & 0.65 & 0.95 \\
Magnet thickness / stack length & 0.10 & 0.20 \\
Rotor yoke thickness / stack length & 0.05 & 0.20 \\
Coil width / max possible coil width & 0.65 & 1.00 \\
\hline
\end{tabular}

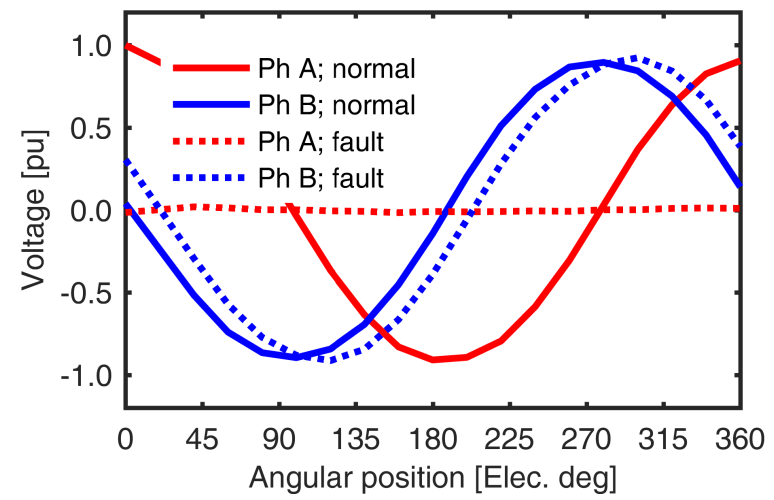

Figure 2. The terminal voltages of the two-phase coreless WAVED motor at normal and faulty phase short circuit operation, illustrating the advantageous decoupling between two phases.

\section{DESIGN OptIMIZATION}

The optimization algorithm implements 3D FEA for design evaluations and is introduced in [14]. These design evaluation are conducted thorough transient analysis in ANSYS Maxwell 3D [15]. The objectives are to minimize the mass and the loss. The optimization is performed for the operation at the rated torque and speed.

The optimization variables include: number of poles, split ratio, pole arc to pole pitch ratio, magnet thickness and rotor yoke thickness (defined as ratios by dividing them by the total axial length), and ratio of the coil width to the maximum possible coil width. The variable limits are given in Table II. The current density for each design is assigned to produce the rated torque. It is observed that designs with smaller dimensions require more than $20 \mathrm{~A} / \mathrm{mm}^{2}$. Therefore, the outer diameter and axial length are fixed at their maximum values in the optimization.

The optimization is performed and the Pareto front for minimum mass and loss are obtained as shown in Fig. 3. The best designs on the Pareto front have 20 to 24 poles. The higher pole count deteriorates both mass and loss. It was observed that selecting a design with a higher loss and less magnet volume can increase the per unit inductance and hence obtain a wider speed range. This is discussed in the next section.

A comparison is conducted with a commercial high efficiency electric motor, the YASA P400 electric motor [16]. The YASA motor produces about the same power but at a lower speed and higher torque compared to the optimally designed coreless machine. Information publicly available for the YASA P400 series reports casing diameter of $305 \mathrm{~mm}$, axial length 


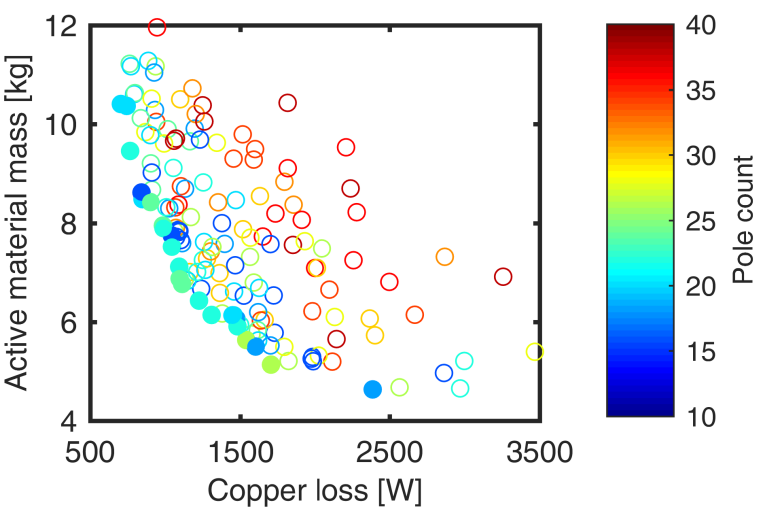

Figure 3. Optimization results for the high speed WAVED motor. The Pareto front designs are shown with filled markers and the color map is for the number of poles.

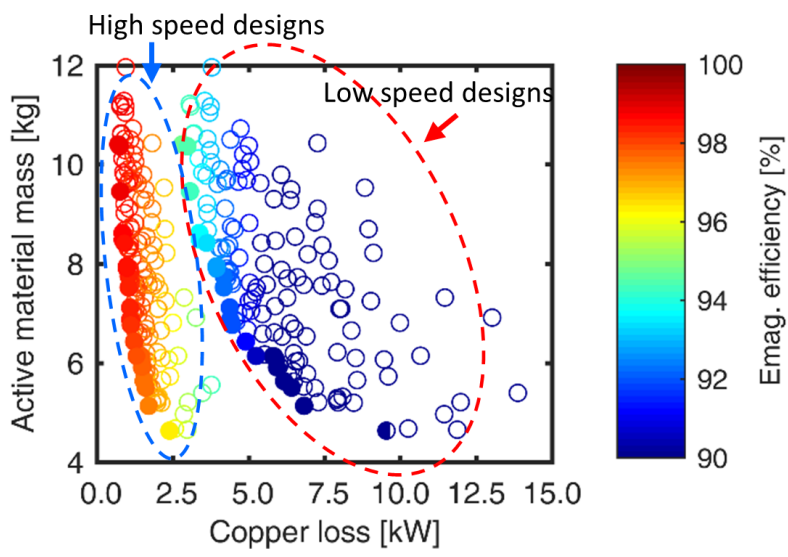

Figure 4. Optimization results for the high speed WAVED motor together with designs obtained by scaling for the higher torque and lower speed at the same power ratings.

of $106.7 \mathrm{~mm}$, at the base speed and torque of 4,000 rpm and $120 \mathrm{Nm}[16]$.

In order to conduct the comparison at identical ratings, the electrical loading of the coreless machines designed at high speed of $10,000 \mathrm{rpm}$ and $60 \mathrm{Nm}$ are scaled to represent the performance at the same ratings of the lower speed YASA motor. The dimensions of the YASA machine are comparable with the coreless topology.

Figure 4 represent the motor efficiency of the designs for the high speed ratings of this study and the lower speed ratings of YASA P400. The Pareto front designs are represented with filled markers. All of the high speed designs included in scatter plots are analyzed through 3D FEA. The electromagnetic efficiency of the coreless WAVED machines are over 95\% and, as expected, increase for heavier designs. The estimated motor efficiency of the YASA P400 configuration is reported to be $93 \%$ including the controller. The coreless machine at low speed has a slightly lower efficiency, with current densities exceeding $15 \mathrm{~A} / \mathrm{mm}^{2}$ however it is lighter. Therefore, it can be stated that the coreless design compared to the YASA machine might be a better candidate if the ratings are at

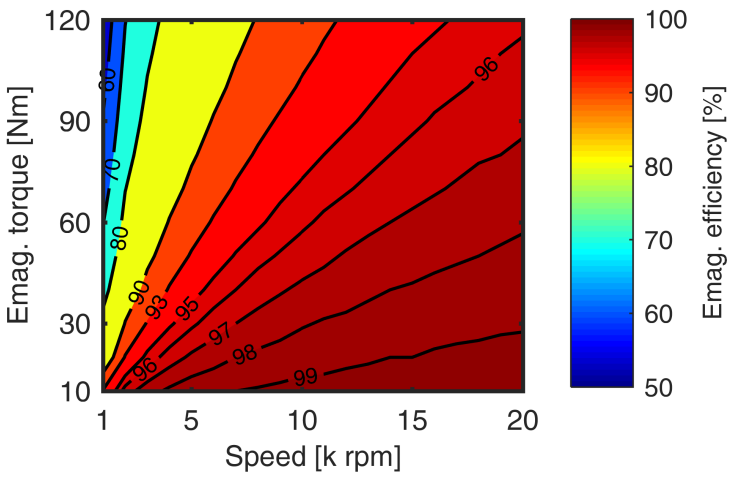

(a)

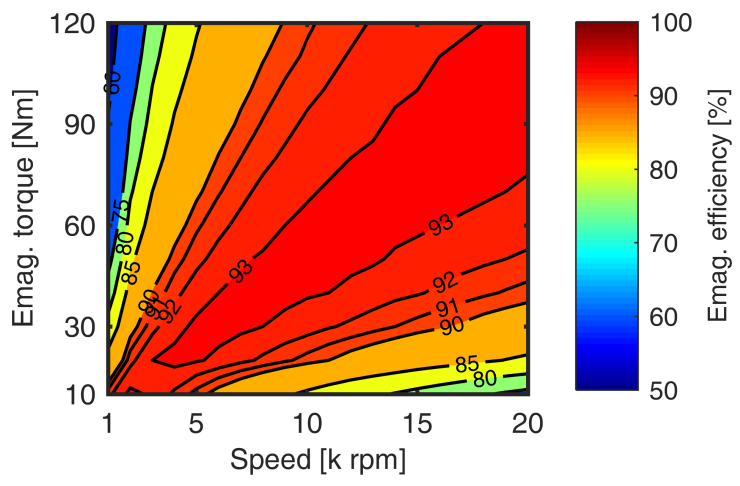

(b)

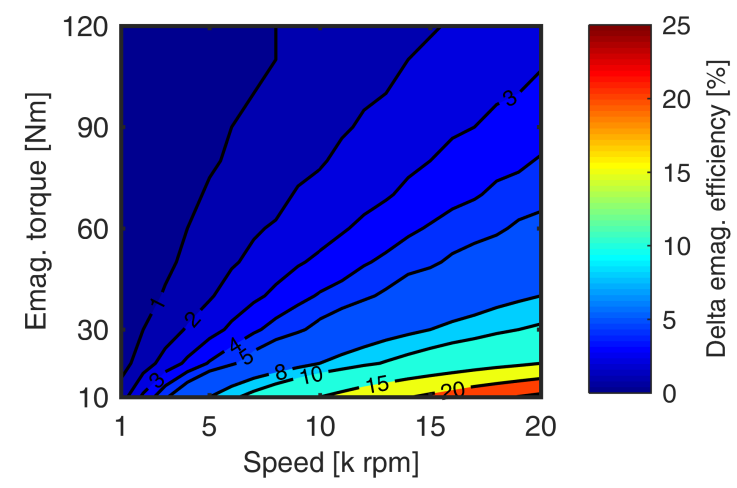

(c)

Figure 5. The efficiency maps obtained for an optimally designed coreles machine rated at $60 \mathrm{Nm}$ and 10,000 rpm: (a) employing Litz wire technology with negligible eddy current losses, (b) without utilizing Litz wire. (c) The reduction in efficiency due to using conventional copper wires, is estimated by subtracting the efficiency shown in Fig. $5 \mathrm{~b}$ from $5 \mathrm{a}$.

a higher speed while at lower speeds the YASA machine performs better.

The efficiency map of the selected optimally designed highspeed coreless machine with $60 \mathrm{Nm}$ ratings and $6.9 \mathrm{~kg}$ active material mass is obtained in two scenarios: once employing Litz wire and hence negligible winding eddy current losses, shown in Fig. 5a, and once taking the eddy current losses in windings into account for copper coils employing American wire gauge size of AWG 20. The increased eddy losses at 


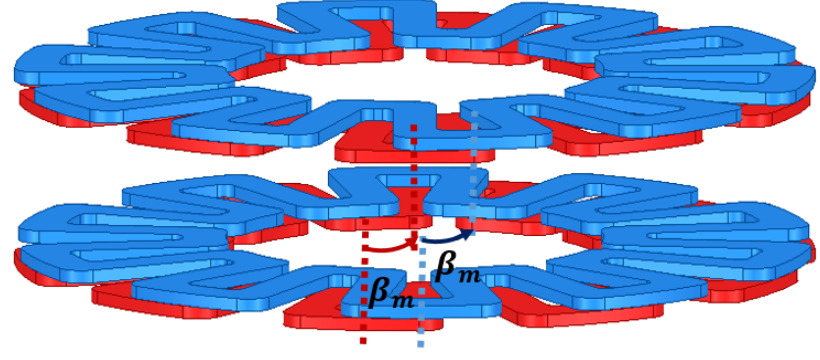

Figure 6. Illustration of the proposed technique for rotation of one of the stators with respect to the other for higher speed operation in constant power zone.

higher speeds are estimated using the following

$$
P_{e d d y}=\frac{\pi \ell N_{c} N_{t} N_{s} d^{4} B_{a}^{2} \omega^{2} \sigma}{128},
$$

where $N_{c}$ is number of coil sides with the length of $\ell ; N_{t}$, turns per coil with circular cross section; $N_{s}$, strands per turn with diameter of $d$; assuming no magnet flux leakage on the end coils and all of the coil region exposed to a space uniform flux density of $B_{a}$ varying sinusoidally in time; $\omega$, the electrical angular speed; and $\sigma$ is the conductivity of the coil. The obtained efficiency map is shown in Fig. 5b.

In order to better illustrate the reduction in the efficiency without utilizing the Litz wire technology, a third plot is presented in Fig. 5c, where the map shown in Fig. 5b is subtracted from the one in $5 \mathrm{a}$, therefore, the higher values correspond to a lower efficiency due to eddy losses at higher speeds. The efficiency of the machine with Litz wire only improves at higher speed. However, without Litz wire, at higher speed and lower torque conditions, the eddy losses become dominant and the efficiency deteriorates.

\section{Constant Power Operation}

The extended speed range above the rated speed can be assessed through the characteristic current, defined as

$$
I_{c h}=\frac{\lambda_{p m}}{L_{d}},
$$

where $L_{d}$ is the d-axis inductance and $\lambda_{p m}$ is the permanent magnet flux linkage which can be calculated by

$$
\lambda_{p m}=\frac{\left(D_{o}-D_{i}\right) k_{w 1} N_{t} k_{v g} \alpha_{i} \tau_{p} B_{r} h_{p m}}{\pi g_{e}},
$$

where $D_{o}$ and $D_{i}$ are outer and inner active diameter; $k_{w 1}$ is the fundamental winding factor; $N_{t}$, number of turns per phase; $k_{v g}$, the ratio between the amplitude of the fundamental wave and the average value of the air-gap flux density; $B_{r}$, the magnet remanence; $\tau_{p}$, pole pitch at the equivalent electromagnetic diameter; $h_{p m}$, the PM length in the magnetization direction; and $\alpha_{i}$, the pole-arc to pole-pitch ratio. The electromagnetic air-gap, presented by $g_{e}$, for the conventional machine can be estimated as

$$
g_{e}=\frac{h_{p m}}{k_{\sigma}}+\mu_{m r} k_{c} k_{s o} g,
$$
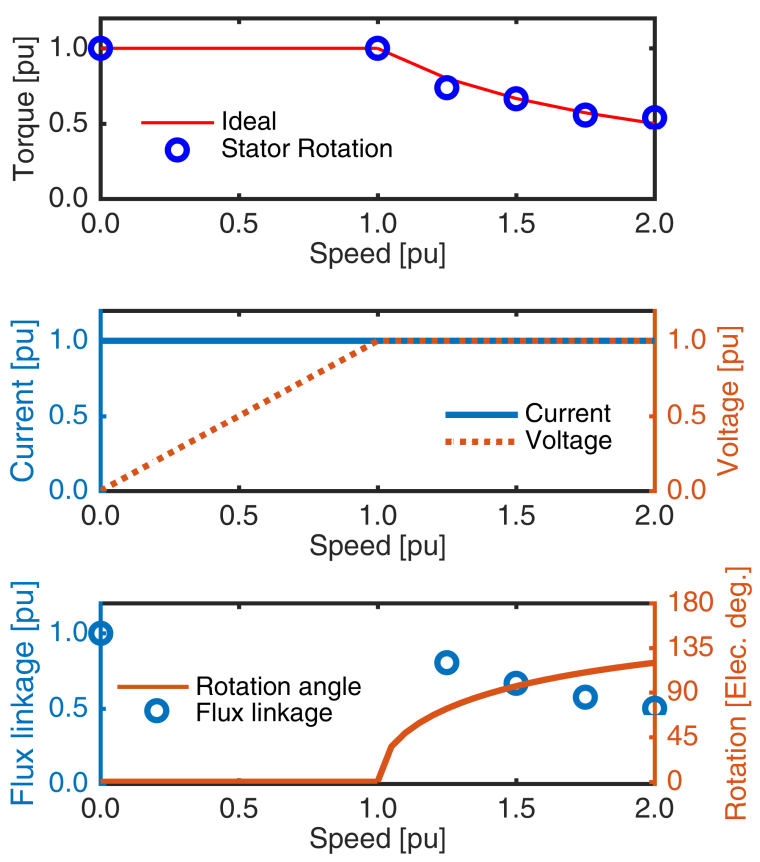

Figure 7. Traction characteristics of a WAVED coreless motor. The proposed stator rotation technique is employed in order to produce constant power operation by reducing the equivalent flux linkage.

and for the coreless machine and as

$$
g_{e}=\frac{h_{p m}}{k_{\sigma}}+\mu_{m r} k_{c} k_{s o}\left(g+L_{c}\right)
$$

where, $k_{c}$ is Carter's coefficient; $\mu_{m r}$, the relative permeability of the PM; $k_{s o}$, the d-axis saturation factor at open-circuit operation; and $k_{\sigma}$, the leakage coefficient; $g$, the mechanical air-gap; and $L_{c}$ is the coil height in axial direction.

The d-axis inductance, $L_{d}$, of an AFPM machine can be estimated as

$$
L_{d}=\frac{m \mu_{0} \tau_{p}\left(k_{w 1} N_{t}\right)^{2}\left(D_{o}-D_{i}\right)}{\pi^{2} p k_{s d} g_{e}},
$$

where $m$ is the number of phases, 2 in this study, and $k_{s d}$, d-axis saturation coefficient.

Theoretically, infinite speed can be achieved when $I_{c h} \leqslant$ $I_{r}$, where $I_{r}$ is the rated current limit. Lower values of $I_{c h}$ adversely affect the delivered power. Therefore, ideally $I_{c h}=$ $I_{r}$. This can be translated to $I_{c h}=1 \mathrm{pu}$.

The rated current of a two phase machine with surface mounted PMs, for a given rated torque, can be evaluated through

$$
I_{r}=\frac{2 T_{e}}{p \lambda_{p m}},
$$

where $T_{e}$ is the electromagnetic torque and $p$ is the number of poles. Incorporating (2)-(7), the per-unit characteristic current can be estimated as 
$\mathrm{S}_{1}$ and $\mathrm{S}_{2}$ : high $\mathrm{f}_{\mathrm{sw}}$

$\mathrm{S}_{3}$ and $\mathrm{S}_{4}$ : low $\mathrm{f}_{\mathrm{sw}}$

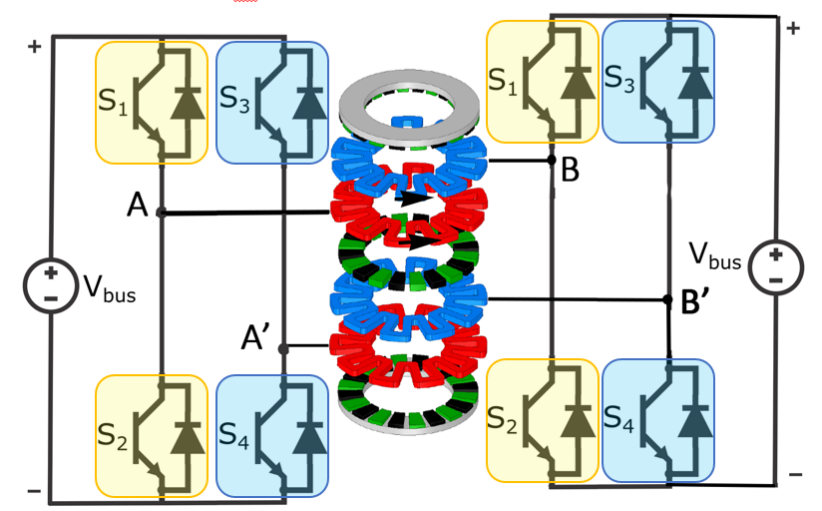

Figure 8. The proposed converter used in conjunction with the WAVED coreless motor. Each phase employs an H-bridge inverter in which one leg operates at higher frequency, $f_{s w}$, while the other operates at lower frequency.
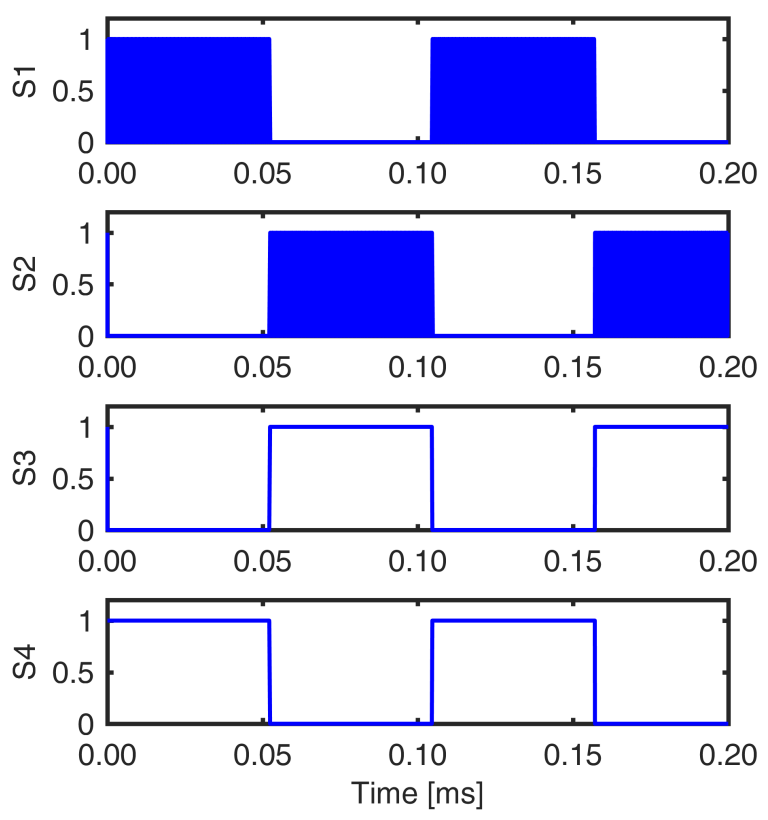

Figure 9. Gating signals for the proposed H-bridge inverter in Fig. 8.

$$
I_{c h, p u}=\frac{\left(1-\alpha_{d}^{2}\right)\left(k_{v g} \alpha_{i} h_{p m} B_{r}\right)^{2} p k_{s d}}{L_{a x} \mu_{0} g_{e} T R V},
$$

where $\alpha_{d}$ is the split ratio; $L_{a x}$ the axial length of the AFPM machine; and $T R V$ is the torque ratio per volume. This indicates that if the machine has a high torque per active volume, $I_{c h, p u}$ reduces, meaning that it may be possible to design high torque density coreless machines with a low characteristic current. In particular, if the same torque per unit volume is obtained with the use of a low magnet volume or a lower remanence, reduced airgap flux density would lead to a low characteristic current. In other words, designs with high

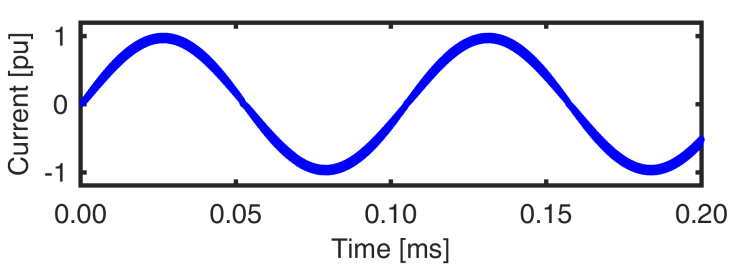

Figure 10. Example current waveform for the inverter in Fig. 8.

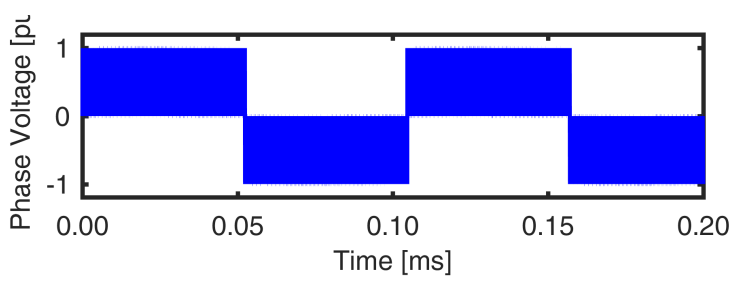

Figure 11. Example voltage waveform for the inverter in Fig. 8.

electric and low magnetic loading, and high torque per unit volume would lead to low characteristic current. These designs would have high loss, and low cost due to low magnet volume.

Two machines, one coreless and the other with stator cores, with similar torque per ampere are considered. Hence $\lambda_{p m}$ is the same and, for the coreless machine, larger or stronger magnets need to be employed. Assuming both machines are employing the same magnet grade, based on (3) the amount of increase in magnet dimensions can be estimated. The coreless machine needs to employ $\left(1+\frac{L_{c}}{g}\right)$ times thicker magnets, i.e. larger $h_{p m}$, than a machine with stator core and the same rated torque. This will significantly increase $I_{c h, p u}$ as derived in (8). The estimated value for the coreless machine under study in this paper is at least $8 p u$.

The increased $I_{c h}$ for the coreless machine limits its speed range. One solution is to employ an inverter with larger ratings [13]. Another method could be to dynamically reduce $\lambda_{p m}$ of the coreless machine. According the approach employed in this paper, this is obtained by utilizing multiple stator discs and rotating them relative to each other.

In the proposed construction two stators are used, each comprising one wave coil per phase. At higher speeds one of the stators can be rotated to reduce the flux linkage and achieve constant power. The required flux linkage reduction at the speed of $n$ where the rated speed is $n_{r}$ can be estimated by

$$
\begin{aligned}
& \frac{n_{r}}{n}=\frac{\sin \frac{k p \beta_{m}}{4}}{k \sin \frac{p \beta_{m}}{4}}=\frac{\sin \frac{p \beta_{m}}{2}}{2 \sin \frac{p \beta_{m}}{4}}=\cos \frac{p \beta_{m}}{4} ; \\
& \beta_{m}=\frac{4}{p} \arccos \left(\frac{n_{r}}{n}\right),
\end{aligned}
$$

where $k$ is the number of stator discs which equals 2 in this case study; $p$, the number of poles; and $\beta_{m}$ is the mechanical rotation angle, as represented in Fig. 6.

This approach is employed for a 20 pole WAVED machine and the 3D FEA results are presented in Fig. 7. At speeds 
higher than the rated value, one of the stators is rotated with respect to the other, reducing the flux linkage and hence torque, resulting in constant power operation. The proposed method successfully achieves ideal high speed operation of the WAVED machine.

\section{Power Electronics Drive with WBG Devices}

Novel machine topologies present new challenges for the design of their accompanying drive systems. Low inductance of coreless topologies will increase current ripple if traditional motor drive switching frequencies are used. Thus, it is necessary to employ wide bandgap (WBG) devices.

A special H-bridge inverter configured with both $\mathrm{Si}$ and WBG devices will be used to drive each phase of the WAVED motor, as illustrated in Fig. 8. This improves fault tolerance due to isolated phases and enables extension of speed range via stator disc rotation. A special technique, unipolar asymmetric pulse width modulation, is employed. This scheme allows one leg of each inverter to switch at fundamental frequency, while the second leg is switched at very high frequencies as shown in Fig. 9. Voltage and current waveforms with low harmonic distortions are still obtained. Example waveforms are provided in Fig. 10 and Fig. 11.

Such an arrangement allows low cost $\mathrm{Si}$ devices to be employed for the leg switching at fundamental frequency, while the WBG devices switching at very high frequencies may be used for the other leg. This configuration would lead to enhanced efficiency, as well as lower cost. This scheme is especially beneficial in conjunction with a 2-phase machine, as only four WBG devices would be required in total, in contrast with a 3-phase drive, which would require six such switches.

\section{CONCLUSION}

The WAVED type axial flux permanent magnet machine proposed in the paper employs two coreless stators with twophase wave windings. A systematic multi-objective optimization study, which considered, in an unconventional approach, the number of poles as an independent variable, indicated that designs with a lower pole count have superior performance and that the higher-loss lower-mass motors have a higher inductance that maybe beneficial for high-speed operation.

Constant power operation, which is required for traction applications, is achieved despite the low inductance specific to coreless designs, through an innovative approach of rotating one stator with respect to the other in order to control the reduction of the flux linkage. The proposed solution addresses one of the major drawbacks that limits the applications of coreless motors. Based on computational analysis it is concluded that a coreless WAVED motor operating at a higher speed and lower torque can produce the same power at a comparable efficiency with a cored machines, such as an example YASA P400 motor. A major benefit of the WAVED machine is that core losses are absent, which becomes extremely important at higher speeds and introduces a new design paradigm by eliminating the efficiency limitations introduced by the properties of the currently available soft magnetic materials.
As illustrated through simulations, the two-phase configuration is also advantageous in terms of fault tolerance due to the magnetic decoupling. Furthermore, the two-phase topology is well suited for a hybrid power electronic H-bridge converter with two legs per phase, one with WBG devices switching at higher frequencies and the other with $\mathrm{Si}$ based devices and switching at a lower frequency, which provides a competitive trade-off between cost and performance.

\section{ACKNOWLEDGMENT}

The support of National Science Foundation NSF Grant \# 1809876, of University of Kentucky, the L. Stanley Pigman endowment and of ANSYS, Inc. is gratefully acknowledged.

\section{REFERENCES}

[1] Z. Q. Zhu and D. Howe, "Electrical machines and drives for electric, hybrid, and fuel cell vehicles," Proceedings of the IEEE, vol. 95, no. 4, pp. 746-765, April 2007.

[2] D. M. Ionel, O. P. Malik, VandanaRallabandi, and N. Taran, "Section 15: Electric machines; motors and drives," in Standard Handbook For Electrical Engineers, Seventeenth Edition. McGraw Hill, 2018, pp. 919-960.

[3] N. Taran, V. Rallabandi, G. Heins, and D. M. Ionel, "Coreless and conventional axial flux permanent magnet motors for solar cars," IEEE Transactions on Industry Applications, vol. 54, no. 6, pp. 5907-5917, Nov 2018.

[4] G. Heins, M. Thiele, D. Patterson, and N. Lambert, "Increase in operating range and efficiency for variable gap axial flux motors," in 2014 IEEE Energy Conversion Congress and Exposition (ECCE), Sep. 2014, pp. 5870-5876.

[5] Electrical and electronics technical team roadmap october 2017. [Online]. Available: https://www.energy.gov/sites/prod/files/2017/11/ f39/EETT\%20Roadmap\%2010-27-17.pdf

[6] J. M. Miller. (2013) 2013 U.S. DOE hydrogen and fuel cells program and vehicle technologies program annual merit review and peer evaluation meeting. [Online]. Available: https://www.energy.gov/sites/ prod/files/2014/03/f13/ape051_miller_2013_o.pdf

[7] "Guest editorial: Advances in high-speed machines for electric drives, power generation and energy storage systems," IET Electric Power Applications, vol. 12, no. 8, pp. 1065-1066, 2018.

[8] F. Caricchi, F. Crescimbini, F. Mezzetti, and E. Santini, "Multistage axial-flux pm machine for wheel direct drive," IEEE Transactions on Industry Applications, vol. 32, no. 4, pp. 882-888, July 1996.

[9] J. F. Eastham, F. Profumo, A. Tenconi, R. Hill-Cottingham, P. Coles, and G. Gianolio, "Novel axial flux machine for aircraft drive: design and modeling," IEEE Transactions on Magnetics, vol. 38, no. 5, pp. 3003-3005, Sep. 2002.

[10] N. Taran, V. Rallabandi, G. Heins, and D. M. Ionel, "Coreless and conventional axial flux permanent magnet motors for solar cars," IEEE Transactions on Industry Applications, vol. 54, no. 6, pp. 5907-5917, Nov 2018.

[11] N. S, S. P. Nikam, S. Singh, S. Pal, A. K. Wankhede, and B. G. Fernandes, "High-speed coreless axial-flux permanent-magnet motor with printed circuit board winding," IEEE Transactions on Industry Applications, vol. 55, no. 2, pp. 1954-1962, March 2019.

[12] F. Marignetti, G. Volpe, S. M. Mirimani, and C. Cecati, "Electromagnetic design and modeling of a two-phase axial-flux printed circuit board motor," IEEE Transactions on Industrial Electronics, vol. 65, no. 1, pp. 67-76, Jan 2018.

[13] D. Lawhorn, N. Taran, V. Rallabandi, and D. M. Ionel, "A comparative study of constant power operation techniques for low inductance machines," in 2018 IEEE Transportation Electrification Conference and Expo (ITEC), June 2018, pp. 638-643.

[14] N. Taran, D. M. Ionel, and D. G. Dorrell, "Two-level surrogate-assisted differential evolution multi-objective optimization of electric machines using 3-D FEA," IEEE Transactions on Magnetics, vol. 54, no. 11, pp. $1-5$, Nov 2018.

[15] ANSYS Electronics Desktop, 2019 R1, 2019.

[16] YASA P400 R series electric motors. [Online]. Available: https://www. yasa.com/wp-content/uploads/2018/01/YASA_P400_Product_Sheet.pdf 